\title{
Carbon Isotope Fractionation during Metabolism of Lactate by Desulfovibrio desulfuricans
}

\author{
By I. R. KAPLAN* AND S. C. RITTENBERG \\ Department of Bacteriology, University of Southern California, \\ Los Angeles, California, U.S.A.
}

(Received 7 May 1963)

\begin{abstract}
SUMMARY
Lactate oxidation during sulphate and sulphite reduction by growing or resting Desulfovibrio desulfuricans resulted in an enrichment of ${ }^{12} \mathrm{C}$ in the $\mathrm{CO}_{2}$ released and also in the cell carbon during growth. The enrichments observed varied between $\delta^{13} \mathrm{C}-5 \cdot 5$ to $-12 \cdot 8 \%$. With sulphite as the oxidant, the fractionation appeared proportional to rate of metabolism of lactate; no definite rate effect on fractionation was suggested by the limited data obtained with sulphate as oxidant.
\end{abstract}

\section{INTRODUCTION}

More studies have probably been made of the distribution of stable carbon isotopes in nature than of any other element (Craig, 1953; Silverman \& Epstein, 1958). The ${ }^{13} \mathrm{C} /{ }^{12} \mathrm{C}$ content of animals, plants, algae and fungi have been measured precisely, yet few experiments have been made to determine fractionation patterns during metabolism. Nier \& Gulbransen (1939) recognized that formation of plant material tended to concentrate the light carbon isotope and Urey (1948) showed that laboratory-cultured algae contained $2.97 \%$ less ${ }^{13} \mathrm{C}$ than the $\mathrm{CO}_{2}$ utilized for growth. Recently Park \& Epstein (1960, 1961) and Abelson \& Hoering (1961) have shown with the tomato plant and with Chlorella sp., respectively, that the lighter isotope is preferentially incorporated into lipids, carbohydrates and proteins during photosynthesis and released during respiration. Using growing cultures of a methane producing bacterium, Rosenfeld \& Silverman (1959) showed that an enrichment of $94 \%$ occurred in the methane liberated during methanol fermentation at $23^{\circ}$. At $30^{\circ}$ there was an increased rate of methane production and a drop in enrichment to $81 \%$. In contrast, metabolic $\mathrm{CO}_{2}$ was only slightly enriched in ${ }^{12} \mathrm{C}$ relative to the methanol $(<4 \%)$ and the enrichment factor was not related to its rate of production.

In the course of investigating the fractionation of stable sulphur isotopes during various processes in the sulphur cycle (Kaplan \& Rittenberg, 1963) some measurements were also made on carbon isotopes, the results of which are reported here. The reactions studied were the oxidation of lactate during sulphate and sulphite reduction by growing and resting Desulfovibrio desulfuricans. The equations representing the overall reactions are:

and

$$
2 \mathrm{CH}_{3} . \mathrm{CHOH} . \mathrm{COOH}+\mathrm{SO}_{4}{ }^{2-} \rightarrow 2 \mathrm{CH}_{3} . \mathrm{COOH}+2 \mathrm{CO}_{2}+\mathrm{S}^{2-}+2 \mathrm{H}_{2} \mathrm{O},
$$

$$
3 \mathrm{CH}_{3} . \mathrm{CHOH} . \mathrm{COOH}+2 \mathrm{SO}_{3}{ }^{2-} \rightarrow 3 \mathrm{CH}_{3} . \mathrm{COOH}+3 \mathrm{CO}_{2}+2 \mathrm{~S}^{2-}+3 \mathrm{H}_{2} \mathrm{O} \text {. }
$$

* Present address: Laboratory for Microbiological Chemistry, Hadassah Medical School, Hebrew University, Jerusalem, Israel. 


\section{METHODS}

Procedures for growth and resting suspension experiments have been described previously (Kaplan \& Rittenberg, 1963).

Metabolic $\mathrm{CO}_{2}$ was swept continuously from experimental flasks by a stream of nitrogen which then passed through two $\mathrm{AgNO}_{3}$ traps to remove sulphide and two traps containing saturated solutions of $\mathrm{Ba}(\mathrm{OH})_{2}$. Experiments were terminated by addition of acid to reaction mixtures which also insured complete release of $\mathrm{CO}_{2}$. The precipitated carbonate was collected on a sintered glass filter, washed with boiling water and dried at $105^{\circ}$. The $\mathrm{BaCO}_{3}$ was treated with sulphuric acid in vacuo to release $\mathrm{CO}_{2}$ for isotopic assay.

The carbon in centrifuged, washed and dried bacteria was converted to $\mathrm{CO}_{2}$ by combustion with oxygen in an apparatus described by Craig (1953).

Isotopic measurements were made on $\mathrm{CO}_{2}$ using a Nier-type dual collection instrument. Isotopic ratios were measured relative to a standard and are reported as $\delta$ values (Kaplan \& Rittenberg, 1963).

Since the studies of Stuven (1960) show that all of the $\mathrm{CO}_{2}$ released during lactate metabolism by Desulfovibrio desulfuricans arises from the carboxyl group, the standard used in the present study was the ${ }^{13} \mathrm{C} /{ }^{12} \mathrm{C}$ of this group. This ratio was determined by measurements on metabolically released $\mathrm{CO}_{2}$ in experiments in which lactate concentration was limiting and its complete degradation occurred.

\section{RESULTS AND DISCUSSION}

Two experiments were run, one with growing cultures and the other with resting suspensions (Table 1). In the growth experiment, three concentrations of lactate were used while sulphate $(0.06 \mathrm{M})$ and temperature $\left(30^{\circ}\right)$ were constant. Both the $\mathrm{CO}_{2}$ and the cell carbon were enriched in the light carbon isotope to approximately the same extent. The range of fractionations observed was small, between $\delta^{\mathbf{1 3}} \mathrm{C}-\mathbf{5 \cdot 5}$ and $-7 \cdot 8 \%$, and the variations did not correlate with either the initial lactate concentration or with the rate of $\mathrm{CO}_{2}$ release. The latter, however, varied by less than a factor of two in the three cultures which may have been insufficient to detect a rate effect on fractionation.

The resting suspension experiments were run at constant lactate $(0 \cdot 12 \mathrm{M})$ and sulphate $(0.06 \mathrm{M})$ or sulphite $(0.06 \mathrm{M})$ concentration but at different temperatures to give a range of rates of lactate oxidation. As with growing cultures, the metabolic $\mathrm{CO}_{2}$ was enriched in the light carbon isotope in all instances. With sulphate as the oxidant, there was an almost fivefold difference in rate of $\mathrm{CO}_{2}$ release at the two temperatures tested but very little difference in the fractionation. With sulphite, however, the degree of fractionation was proportional to the rate of lactate oxidation (Fig. 1).

Lactate oxidation was very slow at $5^{\circ}$, and $18.5 \mathrm{hr}$ were required to collect the desired amount of $\mathrm{CO}_{2}$ for analysis. To determine whether this prolonged contact with sulphite had affected the enzymic activity of the resting bacteria, the temperature of the reaction mixture was raised to and held at $35^{\circ}$ for $1 \mathrm{hr}$, and then lowered to $15^{\circ}$ for the remaining $5 \mathrm{hr}$ of the experiment. The rate of lactate oxidation responded, qualitatively, in the expected manner to these temperature 
manipulations by first increasing and then decreasing. Concurrent with the changes in rate, the fractionation factor for $\mathrm{CO}_{2}$ first increased from $\delta^{13} \mathrm{C}-6 \cdot 9$ to $-9 \cdot 8$, and then fell to $-9 \cdot 1 \%$. It is interesting that in the same experiment the temperature manipulations had quite a different effect on the fractionation of sulphur isotopes, suppressing this phenomenon almost completely (Kaplan \& Rittenberg, 1963).

\section{Table 1. Isotopic fractionation of carbon during lactate metabolism by Desulfovibrio desulfuricans}

$\delta^{18} \mathrm{C}$ measured relative to the ${ }^{19} \mathrm{C} /{ }^{12} \mathrm{C}$ of the carboxyl-carbon of starting lactate.

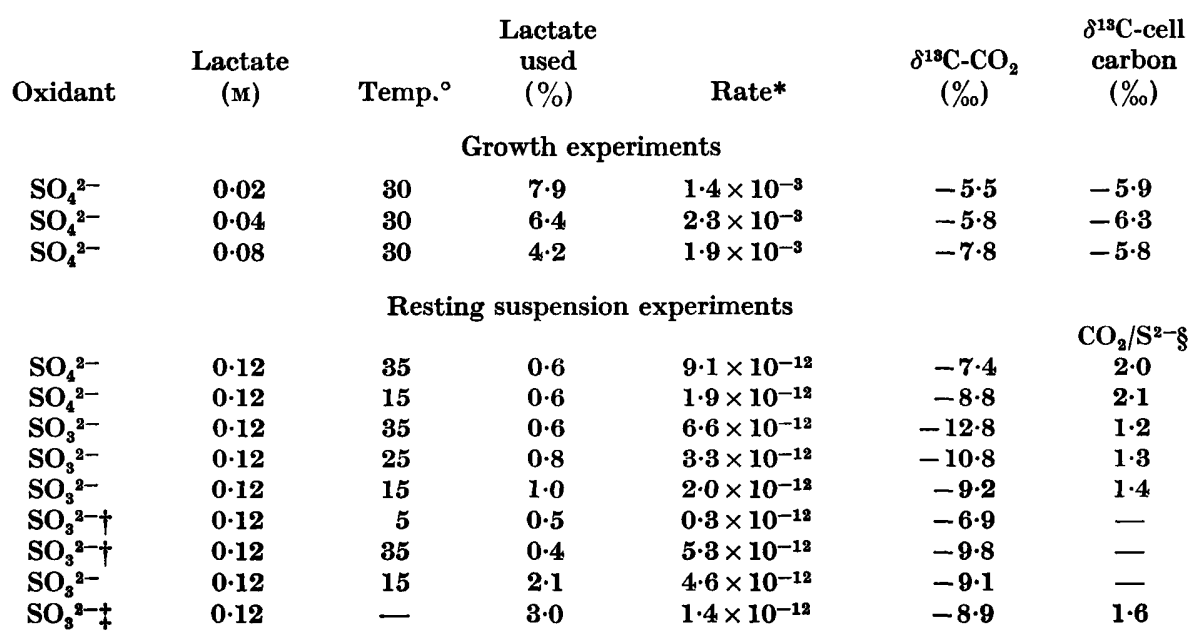

* Rate: $\mathrm{mg}$. carbon released as $\mathrm{CO}_{2} / \mathrm{ml}$. culture/hr for growth experiments; $\mathrm{mg}$. carbon released as $\mathrm{CO}_{2}$ /organism/hr for resting suspension.

$\dagger$ Temperature held at $5^{\circ}$ for $18.5 \mathrm{hr}$, raised to $35^{\circ}$ for $1 \mathrm{hr}$ and lowered to $15^{\circ}$ for $5 \mathrm{hr}$.

$\ddagger$ Weighted averages of the three preceding lines.

$\S$ Molar ratio of products.

The changes in $\delta^{13} \mathrm{C}$ with the temperature fluctuations are in the proper direction if fractionation is proportional to rate of lactate oxidation but the magnitudes of change are less than what would be predicted from the curve established by the other experiments in the series (see $\Delta$ 's, Fig. 1). In the temperature fluctuation experiment it was impossible to add acid to the flask at the end of each $\mathrm{CO}_{2}$ collection period to insure complete release of the gas from the medium. Consequently, part of the $\mathrm{CO}_{2}$ formed at $5^{\circ}$ could have been retained in solution and then released at the higher temperatures. Since such $\mathrm{CO}_{2}$ had a relatively low enrichment of ${ }^{12} \mathrm{C}$, it would have depressed the observed enrichments of the two samples collected at the higher temperatures. Acid was added at the end of the experiment, so the sum of the three portions of $\mathrm{CO}_{2}$ collected represents the total formed. The average rate of $\mathrm{CO}_{2}$ formation over the entire experiment and its $\delta^{13} \mathrm{C}$ were calculated (last line, Table 1). The point determined by these two values falls very close to the curve established by the other data $(O$, Fig. 1). This suggests that, as with fractionation of the sulphur isotopes (Kaplan \& Rittenberg, 1963), it is the rate of the process and not the temperature per se that influences the fractionation of the carbon isotopes. 
It is of interest that the ratio of $\mathrm{CO}_{2} / \mathrm{S}^{2-}$ produced, which from equation (2) should be 1.5, was low at high rates of sulphite reduction and increased as rate of reduction fell (Table 1). No attempt was made to determine whether this phenomenon is related to the pattern of fractionation observed.

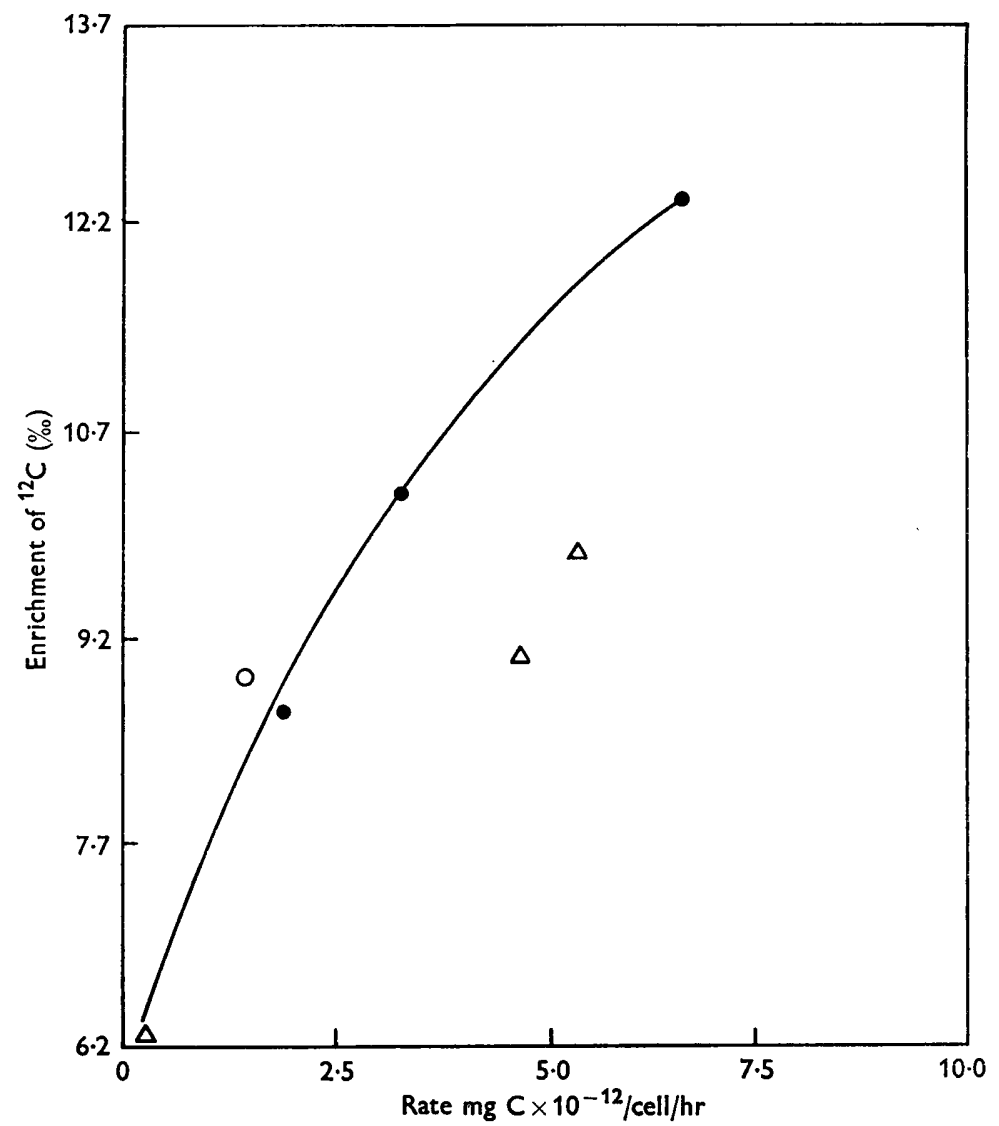

Fig. 1. Enrichment of ${ }^{12} \mathrm{C}$ in metabolic $\mathrm{CO}_{2}$ as a function of its rate of formation during lactate oxidation by Desulfovibrio desulfuricans with sulphite as the oxidant. 0 , Individual experiments at different temperatures; $\triangle$, temperature fluctuation experiment; $O$, weighted average of temperature fluctuation experiment.

It is clear that isotope discrimination occurs during decarboxylation of lactate by Desulfovibrio desulfuricans with the lighter carbon isotope being concentrated in the $\mathrm{CO}_{2}$ released and in carbon assimilated during growth. Fractionations during other decarboxylation reactions have been reported (Lindsay, Bourns \& Thode, 1952 ; Rabinowitz, Lafair, Strauss \& Allen, 1958) and in all cases the $-\mathrm{C}-{ }^{12} \mathrm{C}$ bond cleaved more rapidly than the $-\mathrm{C}-{ }^{13} \mathrm{C}$ or $-\mathrm{C}-{ }^{14} \mathrm{C}$ bonds. The magnitudes of the enrichments observed during the biological oxidation of lactate $\left(\delta^{13} \mathrm{C}-5.5\right.$ to $-12 \cdot 8 \%$ ) are much lower than those reported for methane produced biologically from methanol (Rosenfeld \& Silverman, 1959) but are similar to the $15 \%$ enrichment of ${ }^{12} \mathrm{C}$ in $\mathrm{CO}_{2}$ during non-enzymatic decarboxylation of pyruvic acid (Taylor, 1955). 
We wish to thank Dr S. Epstein, California Institute of Technology and Dr S. Silverman, California Research Corporation, for making the carbon isotope measurements.

This research was supported by a grant from the Petroleum Research Fund administered by the American Chemical Society. Grateful acknowledgement is hereby made to the donors of said fund.

\section{REFERENCES}

Abelson, P. H. \& Hoering, T. C. (1961). Carbon isotope fractionation of amino acids by photosynthetic organisms. Proc. nat. Acad. Sci., Wash. 47, 623.

Craig, H. (1953). The geochemistry of the stable carbon isotopes. Geochim. et cosmoch. Acta, 3, 53.

KAPLAN, I. R. \& RItTEnBerg, S. C. (1963). Microbiological fractionation of sulphur isotopes. J. gen. Microbiol. 34, 195.

Lindsay, J. G., Bourns, A. N. \& Thode, H. G. (1952). Influence of temperature on the intermolecular ${ }^{18} \mathrm{C}$ isotope effect in the decarboxylation of normal malonic acid. Can. J. Chem. 30, 163.

Nier, A. O. \& Gulbransen, E. A. (1939). Variations in the relative abundance of the carbon isotopes. J. Am. chem. Soc. 61, 697 .

Park, R. \& Epstein, S. (1960). Carbon isotope fractionation during photosynthesis. Geochim. et. cosmoch. Acta, 21, 110.

Park, R. \& Epstein, S. (1961). Metabolic fractionation of ${ }^{12} \mathrm{C}$ and ${ }^{13} \mathrm{C}$ in plants. Plant Physiol. 36, 133.

Rabinowitz, J. L., Lafair, J. S., Strauss, H. D. \& Allen, H. C. (1958). Carbon-isotope effect in enzyme systems. II. Studies with formic acid dehydrogenase. Biochim. biophys. Acta, 27, 544.

Rosenfeld, W. D. \& Silverman, S. R. (1959). Carbon isotope fractionation in bacterial production of methane. Science, 130, 1658.

Silverman, S. R. \& Epstein, S. (1958). Carbon isotope compositions of petroleums and other sedimentary organic materials. Bull. Am. Ass. Petrol Geol. 42, 998.

Stuven, K. (1960). Beiträge zur Kenntnis der $\mathrm{CO}_{2}$ - und Lactatassimilation von Desulfovibrio desulfuricans aestuarii (van Delden) Kluyver und van Niel. Arch. Mikrobiol. 36, 31.

TAYLOR, E. W. (1955). Variation of the carbon isotope composition in some natural processes. Thesis. McMaster University, Ontario, Canada.

UrEY, H. C. (1948). Oxygen isotopes in nature. Science, 108, 489. 